\title{
OLASI BİR DEPREMDE KOORDINASYONUN SAĞLANMASI ve SOSYAL MEDYANIN ROLÜ
}

\author{
TÜBA KARAHISAR ${ }^{1}$
}

\begin{abstract}
öz
Çalışmanın amacı deprem sonrasında yaşanmış olan iletişim ve koordinasyon sorunlarını ortaya çıkarmak, olası bir depremde kurumların hangi önlemleri aldıklarını, hangi iletişim teknolojilerini kullandıklarını belirtmek, sosyal medyanın deprem sonrasındaki avantaj ve dezavantajlarını açıklamaktır. Türkiye, 17 Ağustos 1999 depreminin öncesinde ve sonrasında büyük şiddetli depremler yaşasa da 1999 depreminin İstanbul'a yakınlığı, can ve mal kaybının çok olması, yaşanan aksaklıklar, koordinasyon eksikliği, iletişimin tamamen kesilmesi gibi olumsuzluklar, yapılması gerekenler ve halkın bilinçlendirilmesi noktasında milat olmuştur. Elektriklerin kesilmesi, mobil telefonların çalışamaz hale gelmesi neticesinde iletişimin tamamen kopması, hükümet yetkililerinin ilk 48 saat deprem bölgesinden bilgi alamaması; hükümeti, belediyeleri, sivil toplum kuruluşlarını, üniversiteleri afet yönetimi ile ilgili olarak eşgüdüm halinde çalışmaya sevk etmiştir. Geleneksel medya aylarca deprem bölgesindeki ihtiyaçlar, halkın bilinçlenmesiyle ilgili olarak yayın yapmıştır. Sosyal medyanın bir afet durumunda Türkiye'de ilk kullanımı ise 23 Ekim 2011 tarihli Van Erciş depremidir. Çalışmanın yöntemi literatür taramadır. Ayrıca AFAD Kurumsal Iletişim İstanbul Sorumlusu Can Çubukçuoğlu ile 14 Ocak 2014 tarihinde nitel-bireysel görüşsme yapılmıştır. Görüşme, yapılandırılmamış ve açık uçlu olarak gerçekleştirilmiştir. Çalışma sonucunda en önemli sorun, resmi kurumlarda çift yönlü iletişimin olmaması olarak tespit edilmiştir. Deprem sonrasında bürokrasi ve hiyerarşi süreci yavaşlatmaktadır. 1999 depreminden bu güne iletişim teknolojilerinde ve bu teknolojilerin kullanılmasında olumlu gelişmeler kaydedilmiştir. Bilgi akışının hızı olması,
\end{abstract}


bürokrasiden bağımsız hareket edebilmesi, akıllı telefon kullanıcılarının artması, sıklıkla güncellenmesi afetlerde sosyal medya kullanımını etkili kılmıştır.

Anahtar Kelimeler: Afet yönetimi, Deprem, İletişim Teknolojileri, Sosyal Medya, Twitter.

JEL Kodları: D83, D89, Z19.

${ }^{1}$ Dr., tkhisar@gmail.com 
ESTABLISHING COORDINATION in a POTENTIAL EARTHQUAKE and the ROLE of SOCIAL MEDIA

\begin{abstract}
The study aims to reveal the communication and coordination problems experienced after an earthquake, to find out the measures the institutions took against a potential earthquake, to determine the communication technologies they use in case of an earthquake and to explain the advantages and disadvantages of the social media after an earthquake. Although Turkey has experienced severe earthquakes before and after the August 17, 1999 earthquake, the 1999 earthquake has been a milestone in raising an awareness and taking precautions due to the proximity of the earthquake to Istanbul, the loss of too many lives and properties, the lack of coordination, the lack of coordination and the complete interruption of communication. The complete loss of communication due to the failure of mobile communication caused by black outs, and the inability of government officials to obtain information from the earthquake zone in the first 48 hours have led the government, municipalities, NGOs, and universities to work in coordination in response to disaster management. The traditional media has published/broadcast for months to raise awareness about the needs in the earthquake zone. The first use of social media in Turkey in case of a disaster was the Van Erciş earthquake on October 23, 2011. The study incorporated the methodology of literature review. In addition, a qualitative and individual interview was held with Can Çubukçuoğlu, AFAD Istanbul Corporate Communication Manager Responsible, on January 14, 2014. The interview was conducted in an unstructured and open ended manner. As a result of the study, the most important problem identified was the lack of bi-directional communication in official institutions. After an earthquake, bureaucracy and hierarchy slow down the process. Positive developments have been recorded in communication technologies and the use of these technologies since the 1999 earthquake. The rapid flow of information, the ability to act independently from the bureaucracy, the increase in the number of smartphone users, and the frequent updates have made the social media an effective means of communication in disasters.

Keywords: Disaster management, Earthquake, Communication Technologies, Social Media, Twitter.
\end{abstract}

JEL Codes: D83, D89, Z19. 


\section{Giriş}

Deprem, şiddeti ve etkilediği coğrafya ölçüsünde toplumu etkileyen bir afettir. Türkiye, bulunduğu coğrafya sebebiyle depremlere çokça maruz kalmıştır. Ülkelerin yaşadıkları afetlere karşı hazırlıkları, izledikleri politikalar bilinçlendirme ve farkındalık yaratma stratejileri, kurumların nasıl iletişim kuracakları birbirinden farklıdır. 1999 yılında Marmara Bölgesi'ni etkileyen, can ve mal kaybına neden olan depremin ardından yaşanan iletişim ve koordinasyon aksaklıkları, acil durumlarda iletişim sisteminin önemini bir kez daha göstermiştir. Çünkü iletişim, afet sırasında ve sonrasında hasarı, can kaybını önleme adına en önemli konudur. Afet bölgesi ile iletişim kesilirse bölgenin eksiklikleri ve intiyaç analizi bilinemez. Orta şiddette bir depremde karasal haberleşme ağları zarar göreceği için iletişim kesilir. Bu noktada devreye kesintisiz haberleşme sistemi ve sosyal medya kullanıcıları girecektir. Bu sayede ses, görüntü, video, aktarılabilecektir. Çalışmada sosyal medyadan kasıt özellikle Facebook ve Twitter; afet kavramından kasıt ise depremdir.

Türkiye'de sosyal medya kullanımından önce ve sonra deprem bölgesine yapılan yardımlar, kamuda acil haberleşme sistemi, operatörlerin sosyal medya ile bağlantılı uygulamaları, kurumların eşgüdümlü çalışıp çalışmadıkları, afet zamanlarında sosyal medyanın kamu kurumlarınca ne derece ciddiye alındığı çalışmanın konularını teşkil etmektedir. Iletişimde yaşanan aksaklıklar koordinasyona da yansımaktadır: Deprem sonrasında yardıma gelen ekiplerin doğru yönlendirilmemesi, sivil toplum kuruluşları, kamu kurumları ve yardıma gelen yabancı kurumlar arasında yaşanan sorunlar, yetki karmaşası, afetzedelere yemek ve giyecek yardımında yaşanan karışıklıklar vs.

Çalışmanın sorunsalı; deprem sonrasında yaşanan iletişim ve koordinasyon sorunlarının ne boyutta olduğunu, hangi önlemlerin alındığını, konu ile ilgili olarak sosyal medyanın ve mobil uygulamaların önemini durum tespitiyle ortaya koymaktır.

Araştırmanın yöntemi literatür tarama ve nitel-bireysel görüşmedir. Bu amaçla birincil ve ikincil kaynaklardan veri toplanmıştır. Kitap, dergi, bülten ve gazetelerin yanı sıra 19 Kasım 2011 tarihinde "Şehirlerimizin Geleceği Tehditler ve Fırsatlar" Sempozyumu'na, 24 Kasım 2012 tarihinde Afet Yönetim Fuarına, 02 Kasım 2013 tarihinde AFAD'ın (Afet ve Acil Durum Yönetimi Başkanlığı) düzenlediği Güvenli Yaşam Eğitimleri ve 2012 tarihinde AKUT'un (Arama Kurtarma Derneği) düzenlediği Güvenli Yaşam Eğitimlerine dinleyici olarak katılım sağlanarak ve fuarlarda AKUT'un dışındaki sivil toplum 
kuruluşları ile iletişime geçilerek literatür taramasına katkıda bulunması amacıyla dokümanlar toplanmıştır. Depremde sosyal medya kullanımının önemini açıklamak amacıyla ikincil kaynaklara özellikle internete başvurulmuştur.

Konu ile ilgili zengin bir literatür olmasa da son yıllarda araştırmalar yapılmaya başlanmıştır. Ingilizce yayınlar ise sadece deprem değil afet ve kriz iletişimine yoğunlaşmıştır. Genç (2008) makalesinde afetlerde koordinasyon ve iletişimin önemine vurgu yaparken, Zincir ve Yazıcı (2013) ise sosyal medya kullanımının faydalarına değinmiştir. Bruns vd. (2012) sel felaketinde Twitter kullanımı ile iki yönlü iletişime nasıl olanak sağlandığı ve krizin nasıl başarılı şekilde yönetildiğini açıklamışlardır. Türkiye'de depremde sosyal medya ilk kez 2011 yılında Van depremi ile kullanılmıştır. Sarı ve Aksu (2012) çalışmasında yetkililerin deprem anında durum tespiti yaparak ihtiyaçları nasıl hızla belirlediklerini aktarmıştır. Dikkat çeken bir nokta da konunun iletişim bilimcilerden çok işletme bölümü araştırmacıları tarafından irdelenmiş olmasıdır.

Depremde resmi otoriteler, sivil toplum kuruluşları ve halk arasında koordinasyonun nasıl sağlandığı ile ilgili veriler ikincil kaynakların yanı sıra görüşme ile elde edilmiştir. AFAD Kurumsal Iletişim istanbul Sorumlusu Can Çubukçuoğlu ile 14 Ocak 2014 tarihinde nitel-bireysel görüşme yapılmıştır. Görüşme, yapılandırılmamış ve açık uçlu olarak gerçekleştirilmiştir. Ayrıca İstanbul Büyükşehir Belediyesi Afet Koordinasyon Merkezi'nde ve 24 Kasım 2012 tarihinde Afet Yönetim Fuarı'nda gözlem yapılarak arama kurtarma araçları ile ilgili görseller toplanmıştır.

\section{Afet ve Deprem Nedir?}

Birleşmiş Milletlerce yapılan tanıma göre afet "insanlar için fiziksel, ekonomik ve sosyal kayıplara neden olan, normal yaşamı durdurarak veya kesintiye uğratarak toplumları etkileyen ve yerel imkânlarla baş edilemeyen her türlü doğal, teknolojik veya insan kaynaklı tüm olaylardır" (Kadıŏlu, 2008: 1). Doğal afetler biyolojik (salgın hastalıklar), hidrolojik (sel), jeolojik (yanardağ patlaması), jeofiziksel (deprem), meteorolojik (aşırı yağış), ve oşinografik (tsunami) şeklinde sınıflandırılır (Kadıŏlu, 2011a: 41). Bunlara insan kaynaklı afetler, savaş, terörizm de eklenebilir (Talu, 2011: 11). Görüldüğü üzere deprem, pek çok afet olayından biridir. "Depremler, yer içinde birikmiş gerilme enerjisinin aniden boşalmasıdır. Yer içindeki enerji birikiminin nedeni dünyayı saran levhaların hareketleridir". Depremin yeryüzüne çeşitli etkileri bulunmaktadır: 
Heyelanlar, kopmalar, çökmeler, toprak ve çamur akmaları, yangınlar, tsunami vb. (Taymaz, 1999: 72, 73). Dolayısıyla depremler yeni afetlere de sebep olmaktadır.

İstanbul gibi yoğun nüfuslu yerlerde depremler kent depremleri özelliği taşımaktadır. Dolayısıyla maddi ve manevi kayıplar eski depremlere göre artmaktadır. Vatandaşların depremle ilgili bilinçlilik düzeyi, hastanelerin depreme dayanıklılığı, yaşılıarın toplam nüfusa oranı, depremin gündüz mü gece mi olduğu, alt yapının dayanıklılığı, ısınma türü, kurtarma çalışması yapan ekiplerin koordinasyonu gibi etkenler depremin etkisini arttırmakta ya da azaltmaktadır (Arığlu vd., 2000: 185, 186).

\section{Türkiye'de Afetle Illgili Yasal Mevzuat}

T.C. Anayasası'nın 119. Maddesine göre "Tabii afet, tehlikeli salgın hastalıklar veya ağır ekonomik bunalım hallerinde, Cumhurbaşkanı başkanlığında toplanan Bakanlar Kurulu, yurdun bir veya birden fazla bölgesinde veya bütününde süresi altı ayı geçmemek üzere olağanüstü hal ilan edebilir" (T.C. Anayasası: 75). 1939 yılında 39968 kişinin ölümüne neden olan Erzincan depreminin ardından ilk deprem yönetmeliği yayınlanmıştır (Tunçtürk vd., 2012: 54). Hemen ardından yaşanan Niksar-Erbaa, Adapazarı-Hendek, Bolu-Gerede depremlerinde 43000'in üzerinde kişinin ölmesi neticesinde 1944 tarih ve 4623 sayılı Yer Sarsıntılarından Evvel ve Sonra alınacak Tedbirler Hakkında Kanun yürürlüğe girmiştir. 1999 yılında Marmara Bölgesi'nde yaşanan depremin ardından Türkiye Acil Durum Yönetimi Genel Müdürlüğü kurulmuştur. 2009 yılında koordinasyon sorununu gidermek amacıyla 5902 Sayılı Kanun ile afet yönetimi Başbakanlık'a bağlanarak Afet ve Acil Durum Yönetimi Başkanlığı adını almıştır. İllerde ise Valiliğe bağlı ì Afet ve Acil Durum Müdürlükleri oluşturulmuştur. (AFAD 2013-2017 Stratejik Planı, 2012: 15-17). Afete maruz kalan yerlerde valiler sorumlu ve yetkili görevlilerdir. Valinin görevi bir kriz masası oluşturarak kurtarma, hastaları tedavi ettirme, ölüleri defnetme, yangınları söndürme, afetzedelere beslenme ve barınma imkânı sunma gibi görevleri vardır (Keleş, 2007: 19).

\section{Deprem Sonrasında Kurumlar Arası İletişim ve Koordinasyon}

Afet durumunda her kurumun planının, hazırlığının ve hiyerarşik yapısının, tecrübelerinin farklı olması, örgütler arasında çift yönlü iletişimin olmaması, esnek olmayan bir afet müdahale planı, başarısızlığın nedenlerindendir. Gerek ulusal gerekse 
uluslararası kurumların birlikte hareket ettiği network (ağ) modelli yapılanma karmaşıklığın çözülmesine yardımcı olacaktır (Genç, 2008: 166, 167).

"Türkiye'de afetle ilgili kurumlar şunlardır: Bayındırlık ve Iskân Bakanlığı ve bakanlığa bağlı Afet İşleri Genel Müdürlüğü, Teknik Araştırma ve Uygulama Genel Müdürlügü ve Afetler Merkez Koordinasyon Kurulu, Başbakanlığa bağlı Türkiye Acil Durum Yönetimi Genel Müdürlüğü, Başbakanlık Olağanüstü Hal Koordinasyon Kurulu, Başbakanlık Kriz Yönetim Merkezi, Afet inşaat Genel Koordinatörlügü̈, İ̧işleri Bakanlığı ve buna bağlı Sivil Savunma Genel Müdürlügü, Mahalli idareler Genel Müdürlügüu, Arama ve Kurtarma Birlik Müdürlükleri, Sağlık Bakanlığı, Milli Savunma Bakanlığı, Ulaştırma, Çevre ve Orman, Enerji ve Tabi Kaynaklar Bakanlığı, yerel yönetimler, Türkiye Kızılay Derneği" (İsbir ve Genç, 2008: 77, 78).

Ayrıca askeri unsurların donanım ve araçları aracılığı ile deprem bölgesinin keşfi, havadan fotoğraflanması ve iletişim daha kolay sağlanabilir (HOPEFOR-Humanitarian Operation Force, 2012) Örneğin askeri unsurların TUYT (Taşınabilir Uydu Terminali) ile iletişim sağlanabilmektedir (C. Çubukçuoğlu ile kişisel görüşme, 14 Ocak 2014)

Görüldüğü gibi herhangi bir afet durumunda birbirleri ile iletişim kurması gereken kurumların sayısı oldukça fazladır. Ayrıca öncelikle iç haberleşmelerini tamamladıktan sonra kendi aralarında bir ağ oluşturmaları gerekecektir. Bunun da ötesinde yerel yönetimler, valilik, sivil toplum kuruluşları ve depremzede yakınlarının da bu iletişim yumağına eklemlenmesi zorunluluğu vardır.

Başbakanlık Afet ve Acil Durum Yönetimi Başkanlığı'nın yayınladığı Ulusal Afet Müdahale Planı incelendiğinde sosyal medya ile ilgili stratejilere yer verilmediği görülmektedir (Başbakanlık Afet ve Acil Durum Yönetimi Başkanlığı, 2013:15). Afet durumunda iletişim ve koordinasyon açısından yaşanan sorun şudur: Sivil toplum örgütleri, aynı cins kuruluşlar, kamu ve askeri unsurların afet ile ilgili olarak farklı stratejileri, çalışma disiplinleri vardır. Bu çok katmanlı sistemde kimin önder olacağı belli değildir (Titiz, 2000: 336, 337). Stratejik ve operasyonel görevler de birbirine karıştırılmaktadır. Başbakan, bakan veya valilerin görevleri stratejik, sahadaki kişilerin ise operasyoneldir. Stratejik görevi olanlar afetlerde sahaya gelip sorun gidermeye çalışmaktadır. 
Halk da plana dahil edilmelidir. Oysa halk afetlerde sadece afetzede rolündedir (Kadıoğlu, 2011b: 59, 60). Marmara Bölgesi'ni etkileyen 1999 Depremi'nde internet, intiyaçları bildirme ve yardımları ulaştırma konusunda etkin kullanılmıştır. Ancak konuyla ilgili olarak çok sayıda internet sitesinin olması ise koordinasyonsuzluğa neden olmuştur (Akgül, 2000: 334).

Amerika Birleşik Devletleri'nde (A.B.D) afet yönetim sistemi bütünleşik olarak sisteme konulmuştur. Hangi afet olursa olsun yaşanacak sorunlar yemek, barınma, Isınma vb. dir. Tüm kaynaklar ve veriler bir havuzda değerlendirilmekte ve özel sektör de devreye sokulmaktadır (Atlı, 2006: 45). Japonya'da ise resmi kurumlar, itfaiye ile ilgili kurumlar, yerel yönetimler ve halkı birbirine bağlayan ağlar bulunmaktadır (Atlı,2006: 64). Türkiye'de özel sektörü de kapsayan bütünleşik afet yönetim sistemi karmaşayı giderebilir.

\section{a. 1999 Marmara Depremi'nde yaşanan iletişim ve koordinasyon sorunları}

17 Ağustos 1999 Depremi, Marmara Bölgesi, İzmir ve Ankara'ya kadar etkili olmuştur. İmit, Sakarya ve Gölcük'te büyük çapta can ve mal kaybına sebep olmuştur (Aksoy, 2010: 58). Dönemin Cumhurbaşkanı Demirel, 4,5 saat iletişimin tamamen kesildiğini belirtirken (Dündar, 1999: 340) dönemin Başbakanı Ecevit ise ancak telsizle haberleştiklerini, cep telefonlarının dahi çalışmadığını kamuoyuna açıklamıştır (Milliyet, 18 Ağustos 1999). Afetzedeler, telefonlarını şarj edebilmek için kuyruk oluşturmuştur (Anonim, 1999: 69). Marmara Depremi sonrasında medya, afet bölgesinden canlı yayın yaparak halkın bilgilendirilmesi noktasında önemli rol üstlenmiştir. Ulusal gazetelerin internet sayfaları ölü ve yaralıların isimlerini yayınlamış, medya "Bir Tuğla da Siz Koyun" adlı bir çalışma başlatmıştır (Genç, 2008: 168, 169).

Yaşanan bir diğer sıkıntı da kriz masasının oluşturulmamış olmasıdır. Afet bölgesine gelen AKUT vb. kurumlar öncelikle kriz masasından bilgi alırlar ve bu bilgiye göre enkazlarda arama yapmaya başlarlar. Kriz masası kurulmadığı için bilgi toplama işi bu vb. derneklere kalmış ve bu durum vakit kaybına yol açmıştır. Bunun yanı sıra vakit kaybının bir başka sebebi de yardımların ve çalışma makinalarının sadece karayolu ile ulaştırılmaya çalışıımış olması, deniz yolunun hiç tercih edilmemiş olmasıdır (ığdır, 2000: 280). 
Dönemin Değirmendere Belediye Başkanı Akalın yaşanan yetki karmaşasını şu sözlerle açıklamıştır: "Ben su kamyonunun durmasını işaret ettiğimde 'Hayır, polise teslim edeceğiz' dediler. 'Ben belediye başkanıyım' dedim. 'Olsun, kaymakam bizi polise gönderdi' dediler" (Akalın, 2000: 324). İfadelerden anlaşıldığı gibi yetki karmaşası da koordinasyon bozukluğuna neden olmuştur. Depremin 3. Gününde Yalova, Adapazarı ve İzmit ile iletişim kurulamamıştır. Resmi otoritelerle iletişim sağlanamadığı için ilk iki gün ihtiyaçların ve emir komuta zincirinin sağlanması konusunda aksaklıklar yaşanmıştır. En büyük sorunlardan biri de bilgi akışı sağlanmasında birlik kurulamamasıdır. Adres ve şehir krokilerinin güncel olmaması ve hangi yolların kapalı olduğunun bilinememesi sebebiyle kargaşa yaşanmıştır (Genç, 2008: 170-171).

1995 yılında Japonya'nın Kobe kentindeki 7,2 şiddetinde bir deprem yaşanmıştır (Aksoy, 2010: 105). Bu depremde de Türkiye'deki 17 Ağustos 1999 depremindekine benzer iletişim ve koordinasyon eksiklikleri görülmüştür. Bürokrasideki hiyerarşinin esnek olmaması, ilgili bakanlıkların gerçek bilgilere erişmesini geciktirmiştir. Vali, askeri unsurlardan yardım istemekte geç kalmış, yurt dışından gelen doktorların lisansları olmadığı gerekçesiyle çalışmaları istenmemiştir (Barka ve Er, 2002: 138, 139).

Görüldüğü üzere her kurum kendi içinde depreme karşı hazırlıklı olsa bile kimin kimden direktif alacağı, kimin ilk eylemi başlatacağı, ihtiyaç ve yardım listesini medyanın mı, ilgili Bakanlıkların mı, Valiliğin mi bildireceği açık değildir. Her sivil toplum kuruluşu son derece iyi niyetle harekete geçse de sivil toplum kuruluşlarının kendi aralarında bir networkü yoktur.

Türkiye'de de ABD ve Japonya'da olduğu gibi tüm kaynakların ve verilerin bir havuzda toplandığı entegre bir sisteme intiyaç vardır. Böylelikle resmi kurumlar, özel kurumlar, sivil toplum kuruluşları ve halk daha verimli ve hızlı çalışabilecektir (Atlı, 2006: 21).

\section{Kriz Yönetimi, Kamuda ve Özel Sektörde Illetişim}

Risk kavramı "kontrol edilemeyen doğal ve teknolojik tehlikelerin toplumsal ve doğal çevrede olumsuz sonuçlar doğurma olasılığı" olarak tanımlanmaktadır (Yakut, 2008: 13). Kriz yönetimi teknik anlamdaki yönetime odaklanırken kriz iletişimi önlemlerin ilgili kişilerce algılanmasıyla ve buna ilişkin stratejilerin uygulanması ile ilgilidir. Kriz komitesi buna göre öncelikle mevcut durumu tespit eder, kararlar alır ve kararlarını tüm sosyal paydaşlara iletir (Kadıbeşegil, 2008: 55, 78). Risk iletişiminde çift yönlü bilgi 
akışı ve değişimi önemlidir. Riskin ne olduğu ve nasıl baş edileceği, neler yapılması gerektiği noktasında kurumlar arası iletişim olmazsa olmazdır. Bu sayede depreme hazırlıklı olma, erken uyarı sistemini işletme, kurtarma ve iyileştirme mümkün olmaktadır (Yakut, 2002: 118).

Sosyal medya araçları uygulamalarıyla yapılan kriz yönetimi üç evrede incelenebilir: illk aşama olan hazırlık aşamasında önleyici aktivitelere ve riskleri kısıtlamaya odaklanılır. Müdahale aşamasında hızlı ve etkili geri dönüş önemlidir. Bilgileri tam zamanında toplamak, analiz etmek ve yaymak bu aşamada gerçekleşir. Son aşama olan iyileştirme aşamasında ise normale dönmek için uzun dönem planlama gereklidir (Chan,2015: 7).

Deprem olma riski her zaman vardır. Gerek kamu kurumları gerekse özel kurumlar ve bireyler bu riske karşı önlemler almalı ve kriz anında çift yönlü iletişimle üstesinden gelebilmelidir. Kamu kurumlarının ve sivil toplum kuruluşlarının resmi sosyal medya hesabı açması ilk etapta acil yardımlar için çok faydalıdır.

Krizi daha iyi yönetmek, oluşabilecek can, mal ve bina kaybını önlemek için kamu acil haberleşme sistemi ve erken uyarı sistemi gerekmektedir. Kesintisiz haberleşme sistemi için 2008 yılında çalışmalara başlanmıştır. Telsiz sistemi yenilenmiş, telsiz kulesi sayısı arttırılmış ve fiber optik kablolarla sistemin yedeği sağlanmıştır (iBB İstanbul Bülteni, Nisan 2011). "Kamu acil haberleşme sistemi, kamu güvenliği ve acil yardım hizmeti sunmak üzere görevlendirilmiş kurum ve kuruluşlar ve bu alanda faaliyet gösteren birimlerce kullanılacak olan ses, görüntü ve genişband veri iletimine imkân sağlayan yeni nesil kablosuz haberleşme sistemidir". Sistem, kolluk kuvvetleri, AFAD, yerel yöneticiler, sivil toplum kuruluşları ve sağlıkla ilgili birimleri birbirine bağlamayı hedeflemektedir (Nebil, 2015:3).

AFAD Kurumsal İletişim İstanbul Sorumlusu Can Çubukçuoğlu'nun verdiği bilgilere göre Istanbul için yedekli sistemde (3 farklı frekansta) telsiz ve uydu telefon sistemi mevcuttur. Ayrıca 16 adet HF (High Frequency) ve SSB (Single Side Band) her durumda çalışabilen telsizler de vardır. Bu telsizlerle uluslararası görüşmeler sağlanabilmektedir. 23 Ekim 2011 Van depreminde bu sistemden faydalanılmıştır. Diğer kurumlarla bağlantı kurmak, sesli haberleşme yetmediğinde veri ve görüntü transferi için ise VSAT marka uydu internet sistemi kullanılmaktadır. Arazi tipi araçlar iletişimin kesildiği bölgeye giderek bölgenin en son durumuyla ilgili bilgi aktarabilmektedir. Araçta UHFVHF (Ultra High Frequency-Very High Frequency) ve HF- telsizler, uydu telefonu, GSM, 
360 derece dönebilen kamera sistemi bulunmaktadır. Bu araç deprem bölgesinden aldığı her türlü veriyi merkeze aktarmaktadır. 1.5 metre sudan geçen diğer model araç ise kendi elektriğini kendi üretmekte, arama kurtarma yapabilmektedir (C. Çubukçuoğlu ile kişisel görüşme, 14 Ocak 2014). Fakat şu anda kullanılmakta olan TETRA (Terrestrial Trunked Radio) ve DMR (Digital Mobile Radio) gibi sayısal telsiz haberleşme sistemleri yetersiz kalmaktadır. Yüksek çözünürlüklü video iletimi, gerçek zamanlı görüntü iletimi, fotoğraf ve video iletimi için yeni nesil genişband telsiz LTE (Long Term Evolution) yani 4G'yi kullanmak neredeyse zorunlu olmuştur (Nebil, 2015:3).

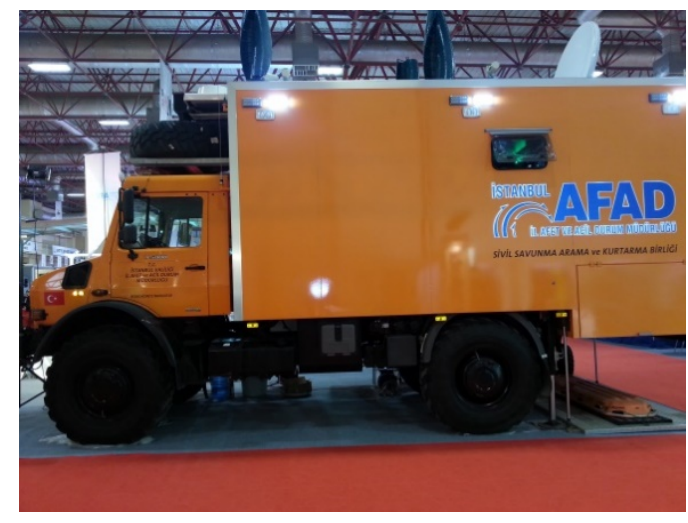

Görsel 1: AFAD Arama Kurtarma Aracı

Kaynak: 24 Kasım 2012 tarihli Afet Yönetim Fuarında Çekilen Görsel

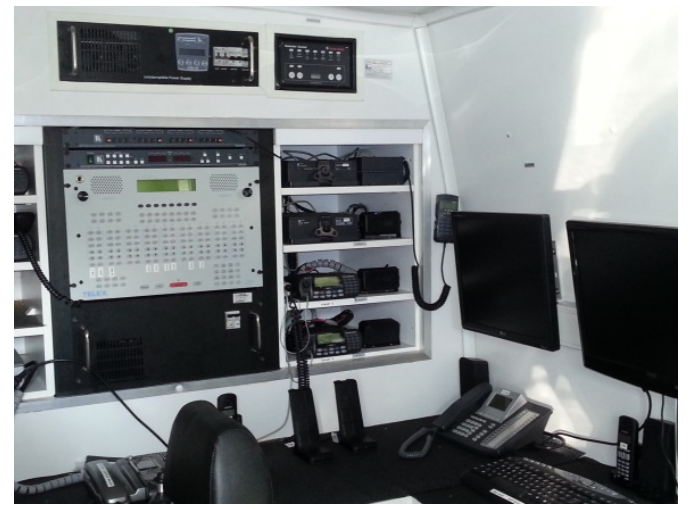

Görsel 2: AFAD Arazi Aracının İçi

Kaynak: 14 Ocak 2014 tarihinde IBB AfetKoordinasyon Merkezinde Çekilen Görsel

ISMEP (İstanbul Sismik Riskin Azaltılması ve Acil Durum Hazırlık Projesi) kapsamında 103.0 frekansından yayın yapan Afet FM kanalından deprem olduğunda kesintisiz güncel verilere ulaşılmaktadır (Güvenli Yaşam, 2016: 5). IBB Afet Koordinasyon Merkezi'nde Kolordu, Emniyet, Kandilli Rasathanesi ve Global Star uydu haberleşme ağı ile direk bağlantı kurulmaktadır (C. Çubukçuoğlu ile kişisel görüşme, 14 Ocak 2014). 
Deprem zararlarını azaltmak amacıyla 2001 yılında başlatılan İstanbul deprem uyarı ve acil müdahale sisteminin çalışmaları halen sürmektedir. Bu sayede 3-15 saniye öncesinde uyarı sinyali almak mümkün olacaktır (Erdik, 2011: 47, 48).

\section{a. Kamu kurumlarının ve özel kurumların depremle ilgili çalışmaları ve mobil uygulamaları}

17 Ağustos 1999 Marmara depreminde yaşanan iletişim aksaklığının ardından başta Bilgi Teknolojileri Kurumu olmak üzere operatörler ve çeşitli kurumlar önlem almaya başlamışlardır. 23 Ekim 2011 Van depreminin ardından Türk Telekom, deprem bölgesindeki müşterileri için tüm görüşmeleri ücretsiz yapmıştır. ADSL (Asimetrik Sayısal Abone Hattı) hizmeti kesintisiz devam etmiştir. Turkcell, 1 ay süreyle ücretsiz 100 dakika ve 100 kısa mesaj hakkı tanımıştır (Dinçer, 2011:1).

Kesintisiz iletişim için ISO 22301'i alan Turkcell deprem anında karşılaşılacak problemlere karşı çalışmalarını hızlandırmıştır. Aynı kalite belgesini alan Vodafone da AFAD ile ortak çalışmalar yürütmektedir. Türk Telekom ile birleşen Avea 'pool' sistemini (ana santral devre dışı kaldığında yedek santralin çalışmaya başlaması) kurmuştur (Çetin, 2014:1).

AFAD, Kandilli Rasathanesi, Türk Kızılayı ve Avea (Türk Telekom) akıllı telefonlar için mobil uygulamalar oluşturmuşlardır. AFAD'ın mobil uygulamasında dünyadan ve Türkiye' den en son depremler, deprem bölgeleri hakkında bilgi verilmiş ve çocuklar için açıklayıcı bir bölüm oluşturulmuştur. Duyurular bölümü güncelleştirilmektedir ve sismograf eklentisi mevcuttur. Kandilli Rasathanesinin hazırlatmış olduğu DBS (Deprem Bilgi Sistemi) adlı uygulama en son depremler, depremlerin tarihçesi, bir deprem hissettim ve çevremde ne var adlı dört başlıktan oluşmakta ancak AFAD'ın uygulaması kadar kapsamlı değildir. Ayrıca uygulamadan çıkış bölümü bulunmamaktadır. Depremin yanı sıra sel, heyelan, orman yangını ve çı̆̆ hakkında bilgi veren, korunma bilincini geliştiren yazılara erişim sağlayan, ilk yardım bilgileri aktaran en kapsamlı uygulama ise Türk Kızılayı'na aittir. Avealabs tarafından geliştirilen Orada Kimse Var mı? Uygulaması son depremler, deprem ipuçları, kişi ekle ve test et bölümlerinden oluşmaktadır. Test et linki tıklandığında sistem güvende olup olunmadığının cevabını istemektedir. Güvende olunduğu belirtilirse, son durumu Facebook ve Twitter'da paylaşma olanağı sunmaktadır. 

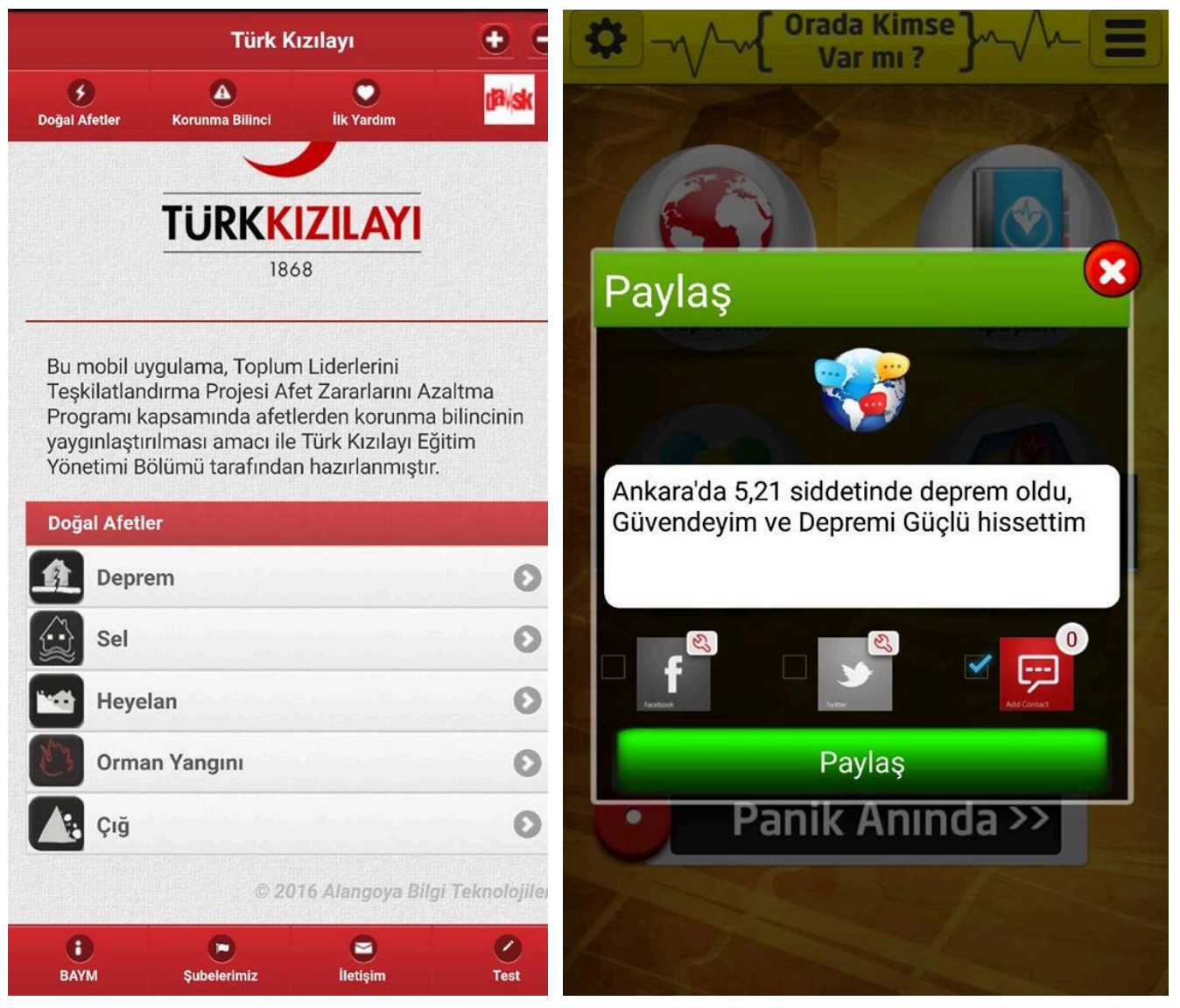

\section{Görsel 3: Türk Kızılayı Mobil Uygulaması Görsel 4: Avealabs'ın Mobil Uygulaması}

Yerel yönetimler, artırımış gerçeklik uygulamalarını başlatmışlar ancak çoğu yarım kalmıştır. Örneğin Bakırköy ve Fatih Belediyelerinin artırımış gerçeklik mobil uygulamaları iptal edilmiştir. Artırılmış gerçeklik, deprem sonrasında pek çok yönden fayda sağlamaktadır: Binanın yeri, hane halkı bilgisi, kaç kişi yaşadığı, yaşı ve engelli vatandaşların olup olmadığı, acil ulaşım güzergâhları, toplanma bölgeleri, zarar görmüş binalar tespit edilebilmektedir. Arama - kurtarma ve lojistik destek konusunda yardımcı olmakta, çevrim dışı da çalışmaktadır. 


\section{Depremde Sosyal Medya Kullanımı}

Afet durumunda kolaylık sağlayacak bir diğer enstrüman da sosyal medyadır. Türkiye'de afet durumunda sosyal medya ilk kez Van depreminde kullanılmıştır. Facebook ve Twitter adeta afet koordinasyon merkezi gibi çalışmıştır. 1 gün içinde bağış kampanyaları, ihtiyaçların temini için yardımlar organize edilmiştir. Sosyal medya kullanıcıları ünlü markaları, depremzedelere bağışta bulunmaları için teşvik etmiştir. (Hazman, 2012:6).

23 Ekim 2011 Van depreminin ardından telefonla iletişim imkânı olmamıştır. Van Vali Yardımcısı Atay Uslu kendi gözlemlerini ve çektiği fotoğrafları sosyal medya aracılığı ile Van Vali'sine aktarmıştır. Depremzedeler yaşadıklarını, fotoğraf ve videolarla paylaşarak yakınları ile iletişim kurabilmişlerdir (Sarı ve Aksu, 2012). Van depreminin ardından program sunucusu Okan Bayülgen'in Twitter takipçileri arasından bir kişi, enkaz altında kalanların konum bilgilerini paylaşmıştır. Bayülgen, bu mesajı AKUT ekibine ileterek iki kişinin hayatının kurtulmasına yardımcı olmuştur (Zincir ve Yazıcı, 2013: 78). Van depreminden sonra 500000 tweet atılmış, Google kişi bulucu ile 4900 kişi takip edilmiştir. \#van, \#EvimEvindirVan, \#deprem, \#kardeslikzamani, \#vanicintekyurek hashtag'leri kullanılmıştır. 9 milyonun üzerinde takipçisi bulunan şarkıcı Rihanna'nın Twitter'da \#pray4turkey hashtag'i ile başlattığı kampanya geniş kesimlere ulaşmıştır. (Kıvılcım, 2012:9). www.yalnizdegilsinvan.com sitesinden deprem bölgesindeki son durum, ihtiyaç listesi güncellenerek paylaşılmıştır (Hazman, 2012:1). 

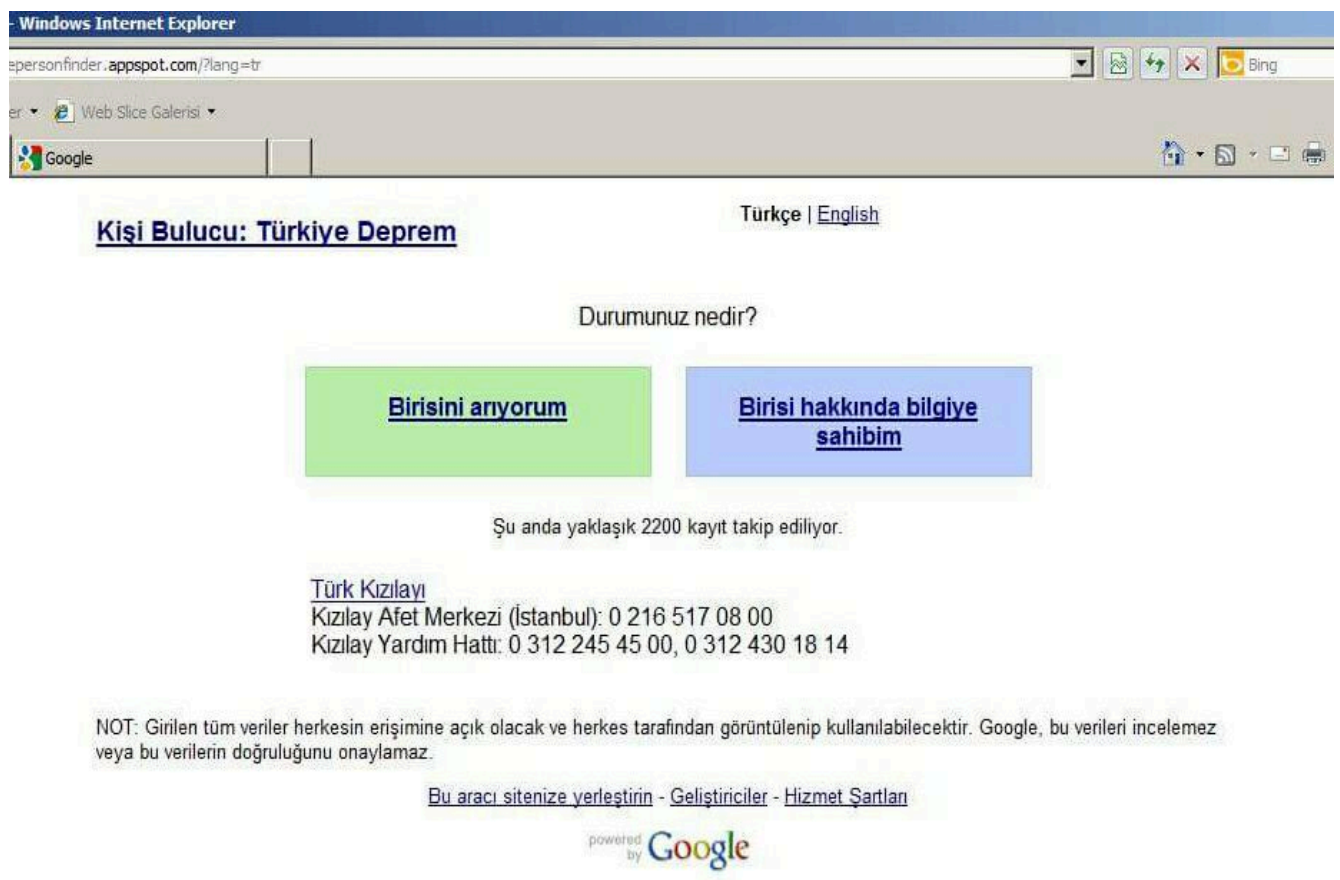

Görsel 5: Google Kişi Bulucu

Kaynak: www.turkey-2011.googlepersonfinder.appspot.com/?lang=tr

10-16 Ocak 2011 tarihinde Avustralya'nın Queensland bölgesinde gerçekleşen sel felaketi Facebook ve Twitter'da kriz iletişimini yönetmek açısından önemli bir örnektir. Queensland yerel yöneticilerinin @QPSMedia hesabı en önemli acil durum hesabı kabul edilmiştir. Yaşanan sel felaketi karşısında Twitterdaki \#qldfloods etiketi sayesinde halk senkronize hareket etmiştir. @QPSMedia hesabı sayesinde sivil halk ve yerel yöneticiler arasında çift yönlü iletişim sağlanmıştır. Toplamda 35000 tweet atılmıştır. \#qldfloods mesajlarının \%50-60 kadarı retweet edilmiştir. Felaketi yaşayanlar, kendi gözlemlerini fotoğraf ve videolar aracılığıyla Twitterdan aktararak ana akım medyaya da kaynak oluşturmuşlardır. @QPSMedia, \#Mythbuster etiketinden yollanan Tweetler sayesinde fısıltı gazetesi ile mücadele etmeyi başarmışlardır (Bruns vd., 2012: 7-9). 
Sosyal medya, depremlerin yanı sıra terör olaylarının ardından kayıpların bulunmasına da yardımcı olmaktadır. Örneğin 13 Mart 2016 tarihinde Ankara Kızılay'da yaşanan patlamanın ardından kayıpların isimleri ve fotoğrafları sosyal medya aracılığıyla yayınlanarak yardım talebinde bulunulmuştur. Kendisi hakkında kayıp ilanı verilenler iyi olduklarını yine aynı mecradan duyurmuştur.
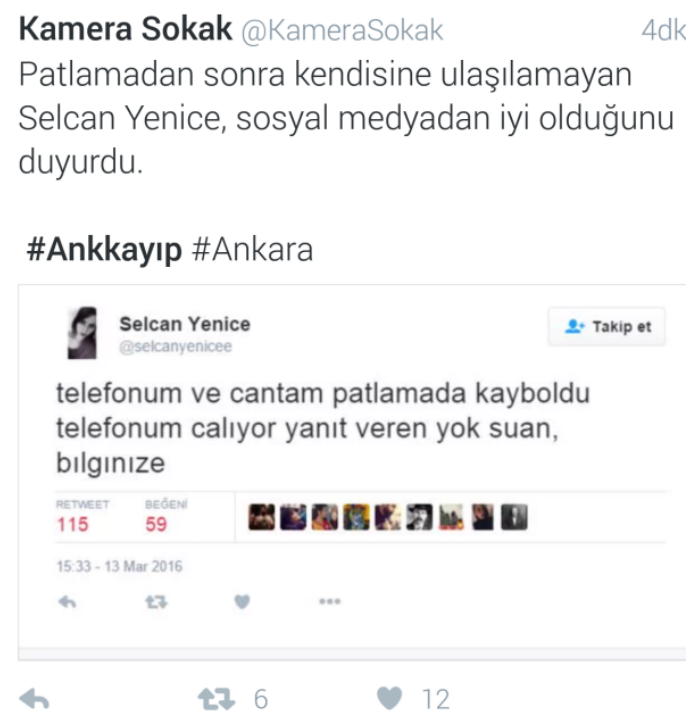

Görsel 6: Twitter'da Kayıp ilanına Cevap

Kaynak: www.twitter.com/KameraSokak

Eşgüdümlü çalışmayan sosyal medyanın depremde faydasından çok zararı da olabilir. Sözgelimi asılsız haberler, kaos, nefret söylemleri, resmi olmayan kaynaklardan alınan haberler üzerine tepkiler, sahte hesaplarla yardım kampanyası başlatanlar vb. Şüphesiz ki koordine edilmiş sosyal medya farkındalık yaratma konusunda çok etkili olmaktadır. Hasar ve can kaybını önlemek için alınacak tedbirler belirli aralıklarla halkla paylaşılabilir. Yerel yönetimlerin desteği ile afet bölgesine ulaşmayı sağlayan yolların, köprülerin durumu resmi otoritelere hızla aktarılabilir. Arama kurtarmanın yanı sıra gıda, barınma, temizlik malzemeleri gibi ihtiyaçlar, mağdurların tespiti, psikolojik destek gibi konular da sosyal medya aracılığıyla düzenlenebilir (Bilişim 2023, 2013:2). 


\section{Sonuç}

Türkiye'de depremle doğrudan bağlantılı pek çok kurum bulunmaktadır. Her kurumun hiyerarşik yapısı, planı ve tecrübesi farklı olduğu için afete müdahale aşamasında sıkıntılar yaşanmaktadır. En önemli sorun çift yönlü iletişimin olmaması ve kriz durumunda yetki karmaşasının yaşanmasıdır. Kimin kimden direktif alacağı ve ilk eylemi kimin başlatacağı net değildir. Bürokrasi ve hiyerarşi süreci yavaşlatmaktadır. Depremde yaşanan koordinasyon sorunları teknik olabileceği gibi fiziksel altyapıdan da kaynaklanabilmektedir. Örneğin her kurumun cihazları farklı, kullandıkları afet dili farklı ve personelin afetle ilgili eğitimi farklıdır. Ayrıca resmi kurumların diğer resmi kurumlarla, resmi kurumların sivil toplum kuruluşları ile ve sivil toplum kuruluşlarının kendi aralarında nasıl iletişim kuracakları net değildir. 1999 Marmara depreminde karasal haberleşme ağları çökmüş, GSM operatörleri çalışmamış, resmi otoriteler, bölge ile uzun süre iletişim kuramamıştır. 1999 Marmara depremi kurumlar arası koordinasyonsuzluğun ve iletişimsizliğin en çarpıcı örneğidir. Çok sayıda can ve mal kaybına sebep olan bu depremin ardından kamu acil haberleşme sistemi kurulmuş, telsiz kapsama alanı genişletilmiştir. AFAD özellikle İstanbul'da iletişim teknolojilerini zenginleştirmiştir. Erken uyarı sistemi için çalışmalar devam etmektedir. Yedekli sistemde ve 3 farklı frekansta telsiz ve uydu telefon sistemi ile uluslararası görüşme yapılabilen sistemleri vardır. AFAD her türlü veriyi merkeze aktarabilen, arama kurtarma yapabilen arazi araçlarını bünyesine katmıştır. Telefon operatörleri de pool sistemini devreye sokmuşlardır. Bunun yanı sıra akıllı telefonlar için mobil uygulamalar geliştirmişlerdir. Yerel yönetimler artırımış gerçeklik çalışmalarına başlamışlar fakat devamını getirmemişlerdir. Oysa çevrim dışı da çalışan bu uygulamalar arama kurtarma ve lojistik destek konusunda çok faydalı olduğu için tekrar gündeme getirilmeli ve kullanıma açılmalıdır.

Sosyal medyanın bir depremde ilk kez kullanımı 2011 Van depremi ile olmuştur. Yerel yönetimlerin Twitter hesaplarını aktif kullanmaları, ünlü kişilerin tweetleri, Van Vali Yardımcısının bizzat bölgede dolaşarak elde ettiği verileri Twitter'da paylaşması, bu sayede intiyaç analizinin kolay yapılması, duyurulması, depremzedelerle yardımseverlerin buluşturulması milat olmuştur. Halk ilk defa depremde çektiği fotoğraf ve videoları ana akım medyaya göndererek işbirliği yapmıştır.

Bilgi akışının hızlı olması ve sürekli güncellenmesinin getirdiği avantajla Twitter resmi otoriteler ile halk arasında bir köprü vazifesi görmüş ve örgütlenme merkezi olmuştur. 
Keza ünlü kişilerin Twitter'da yaptığı yorumlar deprem bölgesine olan hassasiyetin artmasını sağlamıştır. Sosyal medya bürokrasiden uzak, emir komuta zincirinin işlemediği, herkesin paylaşımına açık interaktif bir iletişim mecrasıdır. Resmi otoritelerin sosyal medya hesaplarından halk ile etkileşim halinde olması, can ve mal kaybını azaltacaktır. 2011 Van depreminde devlet, özel sektör, ana akım medya, sivil toplum kuruluşları ve halk sosyal medya sayesinde eş zamanlı olarak iletişim kurabildiği için ihtiyaç analizi doğru yapılmıştır. Bu sayede bağışlar toplanmış, enkazın altında kalanlar kurtarılmış, evsiz kalanlara yardım edilmiştir.

Sosyal medya her şey değildir fakat kriz durumunda çözümün önemli bir enstrümanıdır. İyi yönlendirilirse diğer iletişim araçlarıyla birlikte sürece büyük katkı sağlayacağı açıktır. Tarafların kendi aralarında networklerinin olması iletişimi daha hızlandıracaktır. Örneğin sivil toplum kuruluşlarının kendi aralarında bir networkü, resmi otoritelerin kendi aralarında bir networkünün olması gibi. Tüm verilerin bir havuzda toplandığı ve ilgili tarafların bu havuzdan beslendiği, aynı zamanda kaynak sağladığı bir networke ihtiyaç duyulmaktadır. 


\section{Kaynakça}

AFAD (2012). 2013-2017 Stratejik Planı, Ankara.

Afet Yönetim Fuarı, 24 Kasım 2012.

Akalın, Ertuğrul (2000). Stk'lar ve Merkezi - Yerel Yönetimler, Zeynel Abidin Kızılyaprak (Ed.) Sivil Toplum Kuruluşları ve Yasalar -Etik - Deprem, s. 324, İstanbul: Numune.

Akgül, Mustafa (2000). Stk'lar Arası Illetişimde İnternet, Zeynel Abidin Kızılyaprak (Ed.) Sivil Toplum Kuruluşları ve Yasalar - Etik - Deprem, s. 334, i̇stanbul: Numune.

Aksoy, Yeliz (2010). Tarihteki Önemli Doğal Afetler, İstanbul: Karma.

Anonim (1999). “Deprem Albümü”, Cogito Dergisi, Sayı: 20, s. 69, İstanbul: Yapı Kredi.

Arıoğlu, Ergin, Arıoğlu, Nihal ve Canan Girgin (2000). Deprem ve Kurtarma ilkeleri, İstanbul: Evrim.

Atlı, Ayhan (2006). Afet Yönetimi Kapsamında Deprem Açısından Japonya ve Türkiye Örneklerinde Kurumsal Yapılanma, Ankara: Asil.

AveaLabs'ın Mobil Uygulaması.

Barka, Aykut ve Ali Er (2002). Depremini Bekleyen Şehir istanbul, i̇stanbul: Om.

Başbakanlık Afet ve Acil Durum Yönetimi Başkanlığı, (2013) Ulusal Afet Müdahale Planı.

Bilişim 2023 (2013), http://bilisim2023.com/sosyal-medya/sosyal-medya-da-afetyonetimi-ve-koordinasyonu, (Erişim Tarihi: 21 Nisan 2015).

Bruns, Axel, Bugess, Jean, Crawford, Kate ve Frances Shaw (2012). "\#qldfloods and @QPSMedia: Crisis Communication on Twitter in the 2011 South East Queensland Floods Research Report", http://cci.edu.au/floodsreport.pdf, (Erişim Tarihi: 13 Temmuz 2016).

Can Çubukçuoğlu ile 14 Ocak 2014 tarihinde gerçekleştirilen kişisel görüşme. 
Chan, Jason Christopher (...). "The Role of Social Media in Crisis Preparedness, Response and Recovery", http://oecd.org , (Erişim Tarihi: 10 Eylül 2016).

Çetin, Özgür (2014). "Operatörler Deprem Sonrasına Hazırlanıyor", http:// aljazeera.com.tr/al-jazeera-ozel/operatorler-deprem-sonrasina-hazirlaniyor , (Erişim Tarihi: 10 Ağustos 2015).

Dinçer, Ergun (2011). "Türk Telekom ve Turkcell Van Depremi İçin Destek Planını Açıkladılar", http://turk-internet.com/portal/yazigoster.php?yaziid=34258 , (Erişim Tarihi: 10 Ağustos 2015).

Dündar, Can (1999). "Derinleştikçe Batıyor", Cogito Dergisi, Sayı: 20, s. 340, 341, İstanbul: Yapı Kredi.

Erdik, Mustafa (2011). İstanbul Deprem Erken Uyarı ve Acil Müdahale Sistemi, Mustafa Küçükkural, İsmail Şaşmaz, Nevzat Albayrak, Erkan Baltacı ve Fatih Göksu (Ed.) Şehirlerimizin Geleceği Tehditler ve Fırsatlar, s. 47-51, İstanbul: Over.

Genç, Fatma Neval (2008). "Kriz İletişimi: Marmara Depremi Örneği", Selçuk İletişim Dergisi, 5 (3), s. 161-175.

Google (2011), http://turkey-2011.googlepersonfinder.appspot.com/?lang=tr (Erişim Tarihi: 24 Ekim 2011).

Güvenli Yaşam (2016). http://guvenliyasam.org/103-0-afet-fm/ . (Erişim Tarihi: 3 Haziran 2016).

Hazman, Elif (2012). "Doğal Afetlerde Sosyal Medya Kullanımı", http:// slideshare.net/elifhazman/doal-afetlerde-sosyal-medya , (Erişim Tarihi: 12 Kasım 2015).

Humanitarian Operation Force, (2012). Afetlere Hazırlıkta Askeri ve Sivil Unsurların Koordinasyonu, Antalya.

Iğdır, İskender (2000). Deprem Sonrası Özet Deneyim Aktarımı, Zeynel Abidin Kızılyaprak (Ed.) Sivil Toplum Kuruluşları ve Yasalar - Etik - Deprem, s. 280, İstanbul: Numune. 
İBB İstanbul Bülteni (2011), s. 30, 31.

İsbir, Eyyup ve Fatma Neval Genç (2008). "Afetlere Müdahalede Uluslararası Örgütlerin Rolü: 1999 - Marmara Depremi Örneği”, Amme Idaresi Dergisi, Cilt:41, Sayı: 3, s. 73-97.

Kadıbeşegil, Salim (2008). Kriz Geliyorum Der, İstanbul: MediaCat .

Kadıoğlu, Mikdat (2008). Afet Zararlarını Azaltmanın Temel Illkeleri, Mikdat Kadıoğlu ve Emin Özdamar (der.) Modern, Bütünleşik Afet Yönetimin Temel ilkeleri, No: 2, s. 134, Ankara: JICA Türkiye Ofisi.

Kadıoğlu, Mikdat (2011 a). Afet Yönetimi, Yayın No: 65, İstanbul: Marmara Belediyeler Birliği.

Kadıoğlu, Mikdat (2011 b). “Afet Yönetiminde Neredeyiz?”, Mimar Dergisi, Yıl:11, Sayı: 40, s. 59-62.

Keleş, Ruşen (2007). Afet Yönetimi Açısından Türkiye'de Merkezi ve Yerel Yönetim, Nihal Ekin Erkan, Ayşe Güner ve Katalin Demeter (der.) Afet Risk Yönetimi, İstanbul: Beta.

Kıvılcım, Ayşenur (2012). "Sosyal Medya ve Afet Yönetimi", http://slideshare.net/AyenurKvlcm/sosyal-medya-afet-yonetimi , (Erişim Tarihi: 12 Kasım 2015).

Milliyet, 18 Ağustos 1999.

Nebil, Füsun (2015). "Kamuda Acil Haberleşme Sistemi Koordineli ve Güncel Değil", http://turk-internet.com/portal/yazigoster.php?yaziid=50940, (Erişim Tarihi: 7 Haziran 2016).

Sarı, Mustafa ve Tahsin Aksu (2012). "Afetlerde Sosyal Medya ve Algı Yönetimi: Van Depremi Örneği”, İdarecinin Sesi Dergisi, Temmuz-Ağustos Sayısı, s. 41-46.

T.C. Anayasası, Türkmen Kitabevi, Yayın No:44, s. 75.

Talu, Erdal (2011). Çaresi Var, Yayın No: 632, İstanbul: Türkiye Metal Sanayicileri Sendikası. 
Taymaz, Tuncay (1999). “Deprem”, Cogito Dergisi, Sayı: 20, s. 72-87, Yapı Kredi.

Titiz, Tınaz (2000). Stk'lar Arası İletişimde İnternet, Zeynel Abidin Kızılyaprak (Ed.) Sivil Toplum Kuruluşları ve Yasalar - Etik - Deprem, s. 336, 337, İstanbul: Numune.

Tunçtürk, Yusuf, Özvan, Ali ve Mucip Tapan (2012). Yüzüncü Yıl Üniversitesi 23 Ekim 2011 ve 9 Kasım 2011 Van Depremi Raporu.

Türk Kızılayı Mobil Uygulaması

www.twitter.com/KameraSokak, (Erişim Tarihi: 13 Mart 2016).

Yakut, İnci (2002). "Toplumun Deprem Tehlikesine Karşı Hazırlıklı Olmasında Risk Yönetimi ve Risk İletişiminin Rolü", Kocaeli Üniversitesi İletişim Fakültesi Dergisi, Sayı:1, s. 109-126.

Yakut, İnci (2008). Iletişim Bilimi Perspektifinden Risk Iletişimi Stratejileri, Kocaeli: Umuttepe.

Zincir, Oya ve Selim Yazıcı (2013). "Kriz Yönetimi ve Afetlerde Sosyal Medya Kullanımı", İstanbul Üniversitesi Siyasal Bilgiler Fakültesi Dergisi, Sayı:49, s. 65-82. 